\title{
Concerns in a primary care population about genetic discrimination by insurers
}

Mark A. Hall, JD ${ }^{1}$, Jean E. McEwen, JD, PhD'2, James C. Barton, $M D^{3}$, Ann P. Walker, MA, CGC $C^{4}$ Edmund G. Howe, $M D, J D^{5}$, Jacob A. Reiss, $M D^{6}$, Tara E. Power, $P h D^{7}$, Shellie D. Ellis, $M A^{1}$, Diane C. Tucker, PhD ${ }^{8}$, Barbara W. Harrison, PhD ${ }^{9}$, Gordon D. McLaren, $M D^{4,10}$, Andrea Ruggiero, MA ${ }^{i}$, and Elizabeth J. Thomson, MS, RN ${ }^{2}$

\begin{abstract}
Purpose: Fear of genetic discrimination might deter participation in research or therapy. This is a major impetus for laws limiting insurers' use of genetic information, yet there is little information about the extent of this fear in the general population and how it varies by social factors. Methods: This study measures concern about insurance problems relating to genetic testing, as part of primary-care screening for hereditary hemochromatosis (iron overload). Data come from a multiethnic, primary care-based survey of 86,859 adults in five field centers in the United States (AL, CA, DC, HI, OR), and one in Canada (Ontario). Logistic regression was used to model the probability of agreeing to the question "Genetic testing is not a good idea because you might have trouble getting or keeping your insurance." Results: Overall, 40.0\% of participants agreed. Adjusting for other characteristics, African Americans and Asians were much less likely $(\mathrm{OR}=0.52$ and 0.39$)$, and Hispanics were more likely (OR $=$ 1.124), than Caucasians to express concern about insurance discrimination. Participants under 65 years old, US residents, and those without a high school diploma were substantially more likely to be concerned (ORs ranging from 1.4-1.6), as were participants with lower mental health scores. Education showed a nonlinear relationship, with significantly higher concern among both those with less than a high school education and those with a college degree, compared to high school graduates. Conclusions: Concern about genetic discrimination varies substantially by race and other demographic factors and by nationality. One possible explanation for lower concern about Canadians and by people over 64 is that both groups are covered by social insurance for health care (Medicare). However, US residents in states with some legal protections against genetic discrimination had more, not less, concern than either Canadians or US residents in states with no legal protections. Genet Med 2005:7(5):311316.
\end{abstract}

The potential for genetic discrimination by insurers is a major concern in medical genetics and genetics research, with important public policy implications. Genetic discrimination consists of insurers' limiting or refusing coverage, or increasing their rates, based on genetic information that predicts possible future health problems, before any such problems arise. Although studies of genetic discrimination reveal that its incidence is low, fears of discrimination appear to be widespread. ${ }^{1}$ These fears potentially could deter participation in research, willingness to undergo diagnostic or predictive genetic testing,

From ${ }^{1}$ Wake Forest University, Winston-Salem, North Carolina; ${ }^{2}$ National Institutes of Health-National Human Genome Research Institute, Bethesda, Maryland; ${ }^{3}$ Southern Iron Disorders Center, Birmingham, Alabama; ${ }^{4}$ University of California, Irvine, California; ${ }^{5}$ Uniformed Services University of the Health Sciences, Bethesda, Maryland; ${ }^{6}$ Kaiser Permanente Northwest, Portland, Oregon; ${ }^{7}$ London (Ontario) Health Sciences Center, Ontario, Canada; ${ }^{8}$ University of Alabama at Birmingham, Alabama; ${ }^{9}$ Howard University, Washington, DC; ${ }^{10}$ Veterans Affairs Long Beach Healthcare System, Long Beach, California.

Mark A. Hall, Wake Forest University Medical School, Department of Public Health Sciences, 2000 W. 1st St. Winston-Salem NC 27157-1063.

Received: November 5, 2004

Accepted: January 26, 2005.

DOI: 10.1097/01.GIM.0000162874.58370.CO or implementation of public health screening programs. ${ }^{2}$ These concerns are also a major impetus for state and federal legislation regulating insurers' use of genetic information. ${ }^{2,3}$

There has been limited empirical examination of the extent of fear by the general public about genetic discrimination. ${ }^{4}$ Some studies have focused only on genetic practitioners, such as counselors, ${ }^{1,5-7}$ and thus provide only indirect evidence of the public's concerns. Other studies have focused on people with increased risk for genetic disease, ${ }^{8-11}$ such as women with a family history of breast cancer. ${ }^{12-15}$ It is possible that these individuals have less concern than the general public about discrimination resulting from genetic testing because their family or medical history already indicates some risk. They may also feel greater urgency to undergo testing because of their preexisting risk status and thus are less deterred by the possibility of discrimination.

Previous studies have been limited by relatively small sample sizes, usually only a few hundred and often drawn from only a single location. Few studies have surveyed the general population, ${ }^{16-19}$ which is more relevant to assessing the acceptability of widespread population screening programs. Although they have larger sample sizes (about 2000), they still provide only 
limited opportunity for analysis of socioeconomic and other correlates of these attitudes. As Mayer and colleagues note in summarizing this literature, "if bivariate relationships and characteristics such as age, gender, and education are reported at all, results are presented in a haphazard manner and multivariate relationships are not considered." 19 Previous studies also have not examined if differences in legal conditions or social programs (such as Medicare) might affect concerns about discrimination.

This study adds to our understanding of concerns about insurance discrimination by surveying a very large and racially diverse primary care population participating in a study of iron overload and hereditary hemochromatosis $(\mathrm{HH})$ in both the United States and Canada. It seeks to determine the level of concern and the major demographic and legal factors that explain variations in this concern.

\section{METHODS}

\section{Sample selection}

The data for this analysis come from the Hemochromatosis and Iron Overload Screening (HEIRS) Study, a prospective screening study designed to evaluate the prevalence, genetic and environmental determinants, and potential clinical, personal, and societal impact of hereditary hemochromatosis $(\mathrm{HH})$ and iron overload in a multiethnic, primary care-based population. The study recruited 103,108 adults $\geq 25$ years of age from five field centers, four in the United States and one in Canada. A full description of the study's rationale, design, and methods has been published previously. ${ }^{20}$ The study protocol was approved by Institutional Review Boards at each of the five field centers, the coordinating center and the central laboratory.

Participants were recruited over a 2-year period beginning in March 2001. In three field centers (with clinics in Washington, DC, Orange County, CA, and Birmingham, AL), participants were recruited from among patients at primary care clinics. The Canadian field center recruited participants at clinical laboratories in London and Toronto, Ontario, where they had been referred to have blood drawn. At a fifth field center, with clinics in Portland, OR and Honolulu, HI, participants were recruited from primary care patients in a large health maintenance organization, by direct mail, and at clinics. Study sites and recruitment goals were chosen in order to produce a sample composed of approximately $50 \%$ non-Caucasians.

The primary purpose of the larger HEIRS Study, as explained to participants, was to "find out how many people in the general population have iron overload or $\mathrm{HH}$, what role genes play in iron overload in different populations, and how people feel about having iron tests and gene tests done for these conditions." Participants were told their blood would be tested "to see whether you have too much iron or have the $\mathrm{HH}$ genes that we know about so far." The informed consent form told participants: "If you have iron overload or $\mathrm{HH}$ genes and other people find out, this could possibly lead to problems in employment or in getting or paying for health, life, or disability insurance." The consent form also said that "We will keep your identity, ...your blood test results, and anything you tell us confidential to the best of our ability.... To help insure your privacy, the National Institutes of Health has given us a Certificate of Confidentiality. This means that we cannot be forced to give any information about you to people who are not connected with the study, including courts, without your written consent. However, we cannot guarantee absolute confidentiality."

\section{Measures}

After giving consent to participate in the study, all participants were asked by trained study staff to complete a self-administered questionnaire (with staff assistance as needed). This form collected baseline data on participants' general and mental health status and their general attitudes about genetic testing, in order to observe any changes in these measures after hemochromatosis screening. Recruiters helped subjects with low literacy complete the questionnaire, and questionnaires were offered in one of four languages: English, Mandarin, Vietnamese, or Spanish. Health information was collected via a brief medical history checklist and general health and mental health subscales from the SF-36 Health Survey. ${ }^{21}$ As an indicator of participants' socioeconomic status, an income and education level was assigned to each participant based on the medians reported in the most recent US and Canadian census for each participant's zip code and race/ethnicity. ${ }^{22,23}$ Census figures were further refined by matching to participants' age or gender category.

Attitudes about genetic testing were measured through three questions, each of which asked the respondent's level of agreement (strongly agree, agree, disagree, or strongly disagree) with the following statements: (1) "In general, I think genetic testing to find out about disease risk is a good idea." (2) "I think genetic testing is a good idea because..." ; and (3) "I think genetic testing is not a good idea because...". For items 2 and 3 , respondents were asked their level of agreement about the four separate possible reasons listed in Table 2. The first reason, the focus of this article, proposed that genetic testing might not be a good idea because "You might have trouble getting or keeping your insurance."

Data were entered through a web interface on a secure server at the coordinating center (Wake Forest University) by trained study staff at each of the field centers. Data quality was monitored via double data entry, range and logic checks, and the generation of data edit queries and data quality reports. Six data entry quality control checks of approximately $2 \%$ of participants' responses were performed between April 2001 and August 2003 with a final discrepancy rate of $0.04 \%$.

\section{Statistical analyses}

Descriptive statistics are based on the $84.2 \%(86,859)$ of participants who answered questions about concerns relating to genetic testing. For logistic regression, the analytical sample was further reduced to the $76.6 \%(78,942)$ of participants for whom no data elements were missing. Logistic regression was used to model the probability of answering "Strongly Agree" or 
"Agree" as compared to answering "Disagree" or "Strongly Disagree" to the question "Genetic testing is not a good idea because you might have trouble getting or keeping your insurance." Covariates included nationality, race/ethnicity (White/ Caucasian, Black/African American, Hispanic, Asian, Native Hawaiian/Pacific Islander, American Indian/Alaska Native, or other/mixed/unknown), age group $(<45,45-64$, or $65+)$, education (college degree, at least high school graduate, no high school diploma), attitudes about genetic testing in general, and SF-36 general health and mental health scales. Income was not included because it was correlated with education $(\mathrm{r}=$ $0.328, P<0.0001$ ), and education is probably more directly relevant to attitudes about genetics. Adjusted odds ratios, with $99 \%$ confidence intervals, were assessed to determine what effect each factor has on the concern about genetic discrimination.

\section{RESULTS}

Descriptive statistics for the study population are reported in Table 1 and compared to US Census norms. Consistent with the main study's objectives, non-Caucasian race and ethnic groups were oversampled, and sampling was limited to adults aged 25 years or older. Consistent with recruitment from a general primary care clinical population, the population was older, more female, and in lower general health (self-reported) than US norms. Also, the sample represented a more middle income population that was somewhat better educated, on average, than US norms.

Overall, $40.0 \%$ of participants agreed with the statement that "genetic testing is not a good idea because you might have trouble getting or keeping your insurance" (Table 1). Because our sample is very large, the differences between most comparators are statistically significant. However, views about insurance problems did not differ substantially by nationality or gender. Unadjusted proportions did differ substantially by race, age, income, and education (Table 1), as will be described further later.

Only $2.5 \%$ of participants reported that, in general, genetic testing is a bad idea (Table 1). Among those who reported this view, $47.0 \%$ were also concerned about insurance discrimination. This was only modestly higher than the level of concern about insurance (39.8\%) among those who thought, in general, that genetic testing is a good idea (data not shown).

Among four possible bases for concern about genetic testing (Table 2), concern about insurance discrimination ranked first (39.9\%), above concerns relating to genetic determinism, impact on the family, or feeling less healthy - each of which were indicated by approximately $30 \%$ of participants.

In the multivariate regression analysis (Table 3), all factors were significantly related except for the general health scale (tested at increments of 10 out of 100) and views about whether genetic testing is a good idea in general. African Americans and Asians were much less likely $(\mathrm{OR}=0.52$ and 0.39$)$, and Hispanics were more likely $(\mathrm{OR}=1.124)$, than Caucasians to express concern about insurance discrimination, adjusting for other characteristics. Participants under 65 years old, US residents, and those without a high school diploma were substantially more likely to express concern about insurance discrimination (OR's ranging from 1.4 to 1.6 ), as were participants with lower mental health scores (at increments of 10 out of 100). Surprisingly, education showed a nonlinear relationship with concerns about insurance discrimination, with significantly higher concern among both those with less than a high school education and those with a college degree, compared to high school graduates.

\section{DISCUSSION}

Public concern about insurance discrimination is seen as a major potential barrier to willingness to undergo genetic testing and has been cited as a strong reason for legal protections against insurance discrimination., 2,3,24 Little is known, however, about the extent of these concerns and the impact that protective legislation might have on reducing these concerns. ${ }^{4}$ This is the largest study to date (over 86,000) of public attitudes about genetic discrimination. Forty percent of participants agreed that "genetic testing is not a good idea because you might have trouble getting or keeping your insurance." Caution is warranted in interpreting this finding because the sample was composed of people who had already agreed to participate in a genetic testing study. Therefore, we might expect their views to be biased in favor of genetic testing. Also, the consent form emphasized the confidentiality protections afforded to research participants. On the other hand, the consent form also pointed out the possibility of insurance discrimination and so may have made participants more aware of or concerned about this issue than they would have been otherwise. Regardless, the level of concern we found is similar to that found in previous studies of genetic testing participants ${ }^{10,12,14}$ but is lower than the extent of concern found in previous nationally representative studies of the general population, which ranged from $72 \%$ to $86 \% .{ }^{17}$

Although we could not test directly whether this concern deterred genetic testing, several factors suggest that the concern had only a limited effect on decisions to undergo screening for hereditary hemochromatosis. First, among those who agreed to be tested in the larger hemochromatosis study, concerns about insurance discrimination were only moderately associated with an overall view about whether or not genetic testing is a good idea in general. Adjusting for other characteristics, participants with a positive view of genetic testing generally were no less likely than those with negative views to agree that genetic testing might cause insurance problems (Table 3). It is possible, however, that some participants were expressing that genetic discrimination or losing insurance would be bad if it were to occur to anyone, rather than that they personally felt threatened by genetic discrimination.

To probe this issue further, a different component of the HEIRS Study asked 440 participants who declined genetic screening for hemochromatosis about potential reasons for declining. As reported separately (R.T. Anderson et al, unpublished data, 2005), only $31 \%$ of this sample of decliners agreed 
Table 1

Study population characteristics $[N(\%)$ or Mean \pm SD]

\begin{tabular}{|c|c|c|c|}
\hline & $\begin{array}{l}\text { Agree that "Genetic testing is } \\
\text { not a good idea because you } \\
\text { might have trouble getting or } \\
\text { keeping your insurance" } \\
\text { (\% agreeing) }\end{array}$ & $\begin{array}{c}\text { Overall } \\
\text { (\% of overall) }\end{array}$ & $\begin{array}{l}\text { US Census norms } \\
(\%)\end{array}$ \\
\hline TOTAL & $34,733(39.99 \%)$ & $86,859(100.00 \%)$ & \\
\hline \multicolumn{4}{|l|}{ Nationality } \\
\hline American & $27,560(40.15 \%)$ & $68,647(79.03 \%)$ & \\
\hline Canadian & $7,173(39.39 \%)$ & $18,212(20.97 \%)$ & \\
\hline \multicolumn{4}{|l|}{ Race } \\
\hline Caucasian Only & $19,097(45.38 \%)$ & $42,087(48.45 \%)$ & $75.1 \%$ \\
\hline African American Only & $5,911(30.24 \%)$ & $19,548(22.51 \%)$ & $12.3 \%$ \\
\hline Hispanic & $5,549(52.58 \%)$ & $10,553(12.15 \%)$ & $12.5 \%$ \\
\hline Asian & $2,964(25.14 \%)$ & $11,790(13.57 \%)$ & $3.6 \%$ \\
\hline Native American/Alaskan & $218(38.18 \%)$ & $571(0.66 \%)$ & $0.9 \%$ \\
\hline Pacific Islander & $245(38.58 \%)$ & $635(0.73 \%)$ & $0.1 \%$ \\
\hline Multiple races & $639(46.20 \%)$ & $1,383(1.59 \%)$ & $2.4 \%$ \\
\hline Unknown & $110(37.67 \%)$ & $292(0.34 \%)$ & \\
\hline \multicolumn{4}{|l|}{ Age } \\
\hline$<45$ & $14,007(42.96 \%)$ & $32,604(37.57 \%)$ & $46.7 \%^{*}$ \\
\hline $45-64$ & $16,164(40.70 \%)$ & $39,713(45.77 \%)$ & $34.0 \%{ }^{*}$ \\
\hline $65+$ & $4,514(31.23 \%)$ & $14,456(16.66 \%)$ & $19.2 \% *$ \\
\hline \multicolumn{4}{|l|}{ Gender } \\
\hline Female & $21,907(40.28 \%)$ & $54,388(62.62 \%)$ & $52.1 \%^{*}$ \\
\hline Male & $12,826(39.50 \%)$ & $32,471(37.38 \%)$ & $47.9 \%^{*}$ \\
\hline \multicolumn{4}{|l|}{ Income } \\
\hline$<30,000$ & $4,200(29.35 \%)$ & $14,308(17.77 \%)$ & $35.1 \%$ \\
\hline $30-45,000$ & $10,919(38.89 \%)$ & $28,079(34.88 \%)$ & $17.9 \%$ \\
\hline $45-60,000$ & $10,006(42.18 \%)$ & $23,724(29.47 \%)$ & $14.0 \%$ \\
\hline $60,000+$ & $6,699(46.54 \%)$ & $14,394(17.88 \%)$ & $33.0 \%$ \\
\hline \multicolumn{4}{|l|}{ Education } \\
\hline No high school diploma & $4,386(50.76 \%)$ & $8,641(10.70 \%)$ & $19.6 \% *$ \\
\hline High school graduate & $17,415(35.65 \%)$ & $48,854(60.51 \%)$ & $56.0 \% *$ \\
\hline College degree & $10,117(43.54 \%)$ & $23,236(28.78 \%)$ & $24.4 \%^{*}$ \\
\hline Disagree genetic testing is a good idea in general & $1,007(46.97 \%)$ & $2,144(2.49 \%)$ & \\
\hline General health scale & $67.38 \pm 20.38$ & $67.96 \pm 20.77$ & 72.0 \\
\hline Mental health scale & $72.24 \pm 18.61$ & $74.09 \pm 18.78$ & 74.7 \\
\hline
\end{tabular}

${ }^{\star}$ For comparability, census figures are for the population age $>24$.

with the potential concern that "my information might not be kept private." This concern was ranked fourth among 12 possible concerns, below the following: (1) wanting to talk to their doctor first, (2) wanting more information about the test, and (3) not having time that day. Finally, anecdotal reports from participating field centers indicated that concerns about genetic discrimination were not voiced frequently by those who declined to participate during recruitment. Still, it is likely that this concern was a factor in the decision of some decliners.

Due to this study's large sample size, statistical significance was found for most factors that were examined. Therefore, we focus more on the magnitude of the relationships observed. Race/ethnicity was the strongest of the demographic factors. African Americans and Asians were much less likely than Cau- 
Table 2

Reasons genetic testing is or is not a good idea $[N(\%)]$

\begin{tabular}{|c|c|c|}
\hline & Agree & Disagree \\
\hline \multicolumn{3}{|l|}{ I think genetic testing IS a good idea because. . . } \\
\hline There might be a good treatment by the time you developed the disease & $84,563(98.03 \%)$ & $1,700(1.97 \%)$ \\
\hline You could change to a healthier lifestyle to prevent getting the disease & $84,424(97.82 \%)$ & $1,882(2.18 \%)$ \\
\hline You could prepare better for the future & $84,310(97.86 \%)$ & $1,841(2.14 \%)$ \\
\hline You could share this information with family members & $83,804(97.22 \%)$ & $2,392(2.78 \%)$ \\
\hline \multicolumn{3}{|l|}{ I think genetic testing IS NOT a good idea because. . . } \\
\hline You might have trouble getting or keeping your insurance & $34,733(39.99 \%)$ & $52,126(60.01 \%)$ \\
\hline You might feel helpless because you can't change your genes & $26,186(30.36 \%)$ & $60,077(69.64 \%)$ \\
\hline Knowing that you had a gene that put you at risk could make you feel less healthy & $26,546(30.84 \%)$ & $59,517(69.16 \%)$ \\
\hline You could be bringing bad news into your family & $26,441(30.82 \%)$ & $59,351(69.18 \%)$ \\
\hline
\end{tabular}

Table 3

Logistic regression analysis probability of agreeing that genetic testing might cause insurance problems

\begin{tabular}{lcc}
\hline Covariate & $\begin{array}{c}\text { Odds } \\
\text { ratio }\end{array}$ & $\begin{array}{c}\text { Confidence } \\
\text { interval }\end{array}$ \\
\hline Race Black/A-A vs White & 0.518 & $0.490-0.548$ \\
Ethnicity Hispanic vs White & 1.124 & $1.027-1.230$ \\
Race Asian vs White & 0.394 & $0.369-0.419$ \\
Race other/unknown vs White & 0.864 & $0.770-0.969$ \\
Age 25-44 vs 65+ & 1.652 & $1.553-1.758$ \\
Age 45-64 vs 65+ & 1.505 & $1.419-1.596$ \\
American vs Canadian & 1.384 & $1.303-1.469$ \\
${ }^{*}$ Genetic testing is good generally (Agree vs Disagree) & 0.930 & $0.823-1.051$ \\
${ }^{*}$ General health scale, 10\% increments & 1.006 & $0.995-1.017$ \\
Mental health scale, 10\% increments & 0.934 & $0.923-0.945$ \\
Education less than HS vs high school grad & 1.407 & $1.331-1.488$ \\
Education college degree vs high school grad & 1.236 & $1.127-1.356$ \\
\hline${ }^{*}$ non-significant & &
\end{tabular}

* non-significant

casians to report concern that genetic testing could lead to insurance discrimination, after adjusting for age and imputed education, whereas Hispanics were more likely to express this concern. In results not shown, we tested for whether these relationships endured after adjusting for income as well as education (imputed by zip code averages). In this alternative model, African Americans and Asians remained significantly less concerned, but Hispanics were no longer more concerned. This suggests that a mix of socioeconomic factors relate to these attitudes in complex ways that differ among racial and ethnic groups.

People 65 and over were substantially less likely to be concerned that genetic testing could lead to insurance discrimination. This may be due to the protections afforded by Medicare coverage. Similarly, Canadians were less likely to express this concern, possibly because they have national health insurance. The pattern of lower concern among those covered by socialized insurance programs suggests that concerns about genetic discrimination are driven in part by the vulnerabilities created by private health insurance.

As an exploratory analysis, we also examined whether the likelihood of concern varied by the status of state laws protecting against genetic discrimination. Among our study locations, Alabama and Washington, DC, have no relevant legal protections, and the Western states covered by the other two field centers (California, Oregon, and Hawaii) have substantial but not complete protections against discrimination by health insurers. ${ }^{24}$ For instance, Hawaii regulates use of genetic information only by health insurers who cover individuals and not groups, and none of these states protect people who purchase insurance in a different state. Contrary to expectation, participants in states with some protective laws (California, Oregon, and Hawaii) had greater concern relative to Canadians ( $\mathrm{OR}=$ 1.37), whereas the concern in locations with no legal protections (Alabama and DC) was not statistically different from Canada, adjusting for demographic factors. Apse and colleagues ${ }^{9}$ reported that at-risk relatives of colorectal cancer patients had only minimal awareness and understanding of protective laws. It appears, then, that factors other than the simple existence of these laws account for differences based on nationality or jurisdiction. One possibility is that awareness of genetic discrimination might be greater in states with legal protections. If so, greater awareness might have caused these states to adopt the protection, or greater awareness might have resulted from publicity created by the legal enactments. We were not able to test for these possibilities.

The nonlinear relationship we found between education and likelihood of concern is somewhat puzzling. Both college graduates and those without a high school diploma were more likely to express concern than were high school graduates. This finding should be interpreted cautiously, however, because education levels were imputed from zip codes rather than mea- 
sured directly. Determining how and why education is related to discrimination concerns will require further study.

This study is limited by several factors. First, we assessed concerns about insurance discrimination using only a single question that referred to insurance in general rather than specifying a type of insurance (e.g., health vs. life). Second, this study was conducted among participants who had already agreed to undergo genetic screening for a particular condition (hemochromatosis) and were told this could cause insurance problems, and so the study does not reflect the unprompted views of the general public regarding other genetic conditions. Nevertheless, this study supports the view that public concerns about genetic discrimination are substantial. Also, the findings are consistent with the view that social insurance programs might help to alleviate these concerns. Future studies should focus on explanations for different levels of concern among racial/ethnic minorities, on possible concerns about other forms of discrimination, such as employment, and on whether reducing these concerns will increase willingness to undergo genetic testing or to participate in genetic research studies.

\section{ACKNOWLEDGMENTS}

The HEIRS Study was initiated and funded by the National Heart, Lung, and Blood Institute, in conjunction with the $\mathrm{Na}$ tional Human Genome Research Institute. The study is supported by contracts N01-HC05185 (University of Minnesota), N01-HC05186 (Howard University), N01-HC05188 (University of Alabama at Birmingham), N01-HC05189 (Kaiser Permanente Center for Health Research), N01-HC05190 (University of California, Irvine), N01-HC05191 (London Health Sciences Centre), and N01-HC05192 (Wake Forest University). Additional support was provided by the Howard University General Clinical Research Center (GCRC) grant, M01-RR10284, and the UCSD/UCI Satellite GCRC grant, M01-RR00827 (University of California, Irvine), sponsored by the National Center for Research Resources, National Institutes of Health. HEIRS Study investigators are listed at https://www.heirs-study.org/PP_Policy.htm

\section{References}

1. Hall MA, Rich SS. Patients' fear of genetic discrimination by health insurers: The impact of legal protections. Genet Med 2000;2:214-221.

2. Collins FS, Watson JD. Genetic discrimination: Time to act. Science 2003;302:745.

3. Rothenberg KH, Terry SF. Before it's too late: Addressing fear of genetic information. Science 2002;297:196-197.
4. Hellman D. What makes genetic discrimination exceptional? Am J Law Med 2003; 29:77-116.

5. Matloff ET, Shappell H, Brierley K, Bernhardt BA, McKinnon W, Peshkin BN. What would you do? Specialists' perspectives on cancer genetic testing, prophylactic surgery, and insurance discrimination. J Clin Oncol 2000;18:2484-2492.

6. Pfeffer NL, Veach PM, LeRoy BS. An investigation of genetic counselors' discussions of genetic discrimination with cancer risk patients. J Genet Counsel 2003;12:419438.

7. Cho MK, Sankar P, Wolpe PR, Godmilow L. Commercialization of BRCA 1/2 testing: Practitioner awareness and use of a new genetic test. Am J Med Genet 1999;83: $157-163$.

8. Lapham EV, Kozma C, Weiss JO. Genetic discrimination: Perspectives of consumers. Science 1996;274:621-624.

9. Apse KA, Biesecker BB, Giardiello FM, Fuller BP, Bernhardt BA. Perceptions of genetic discrimination among at-risk relatives of colorectal cancer patients. Genet Med 2004;6:510-516.

10. Hadley DW, Jenkins J, Dimond E, Nakahara K, Grogan L, Liewehr DJ et al. Genetic counseling and testing in families with hereditary nonpolyposis colorectal cancer. Arch Intern Med 2003;163:573-582.

11. Geer KP, Ropka ME, Cohn WF, Jones SM, Miesfeldt S. Factors influencing patients' decisions to decline cancer genetic counseling services. J Genet Counsel 2001;10:2540 .

12. Armstrong K, Calzone K, Stopfer J, Fitzgerald G, Coyne J, Weber B. Factors associated with decisions about clinical BRCA 1/2 testing. Cancer Epidemiol Biomarkers Prev 2000;9:1251-1254.

13. Peterson EA, Milliron KR, Lewis KE, Goold SD, Merajver SD. Health insurance and discrimination concerns and BRCA 1/2 testing in a clinic population. Cancer Epidemiol Biomarkers Prev 2002;11:79-87.

14. Lynch HT, Lemon SJ, Durham C, Tinley ST, Connolly C, Lynch JF et al. A descriptive study of BRCA1 testing and reactions to disclosure of test results. Cancer 1997; 79:2228.

15. Thompson HS, Valdimarsdottir HB, Duteau-Buck C, Guevarra J, Bovbjerg DH, Richmond-Avellaneda $\mathrm{C}$ et al. Psychosocial predictors of BRCA counseling and testing decisions among urban African-American women. Cancer Epidemiol Biomarkers Prev 2002;11:1579-1585.

16. Rothstein MA. Pharmacogenomics: Social, ethical, and clinical dimensions. New York: John Wiley \& Sons, 2003.

17. Singer E, Corning A, Lamias M. Genetic testing, engineering, and therapy: Awareness and attitudes. Public Opinion Q 1998;62:633-664.

18. Rothstein MA. Genetics and life insurance. Cambridge, Mass: MIT Press, 2004.

19. Mayer RN, Smith NR, Zick CD, Botkin JR. Coercion, control, and consequence in genetic testing. In: Thompson AK, Chadwick RF, eds. Genetic information. New York: Kluwer Academic/Plenum Publishing, 1999:41-56.

20. McLaren CE, Barton JC, Adams PC, Harris EL, Acton RT, Press N et al. Hemochromatosis and Iron Overload Screening (HEIRS) study design for an evaluation of 100,000 primary care-based adults. Am J Med Sci 2003;325:53-62.

21. Hays R, Sherbourne C, Mazel R. The RAND 36 item health survey. Health Economics 1993;2:217-227.

22. Krieger N. Overcoming the absence of socioeconomic data in medical records: Validation and application of a census-based methodology. Am J Pub Health 1992;82: $703-710$.

23. Krieger N, Chen JT, Waterman PD, Soobader MJ, Subramanian SV, Carson R. Choosing area based socioeconomic measures to monitor social inequalities in low birth weight and childhood lead poisoning: The Public Health Disparities Geocoding Project (US). J Epidemiol Community Health 2003;57:186-199.

24. Klanica K. Genetic information and health insurance: a report on law and legislation in the United States. Boston, Mass: Council for Responsible Genetics, 2004. 